\title{
FTIR-ATR Analysis, Curve Fitting of Rigid PVC Tube Used in Industrial Areas
}

\author{
Zineb Hadj amar ${ }^{1, *}$ Salem fouad Chabira ${ }^{1}$ Mohamed Sebaa ${ }^{1}$ \\ ${ }^{1}$ Mechanics Laboratory (lme), University of Amar Telidji, Ghardaïa Road, B.P. 37G, 3000, Laghouat, Algeria \\ *Corresponding author. Email: z.hadjamar@lagh-univ.dz
}

\begin{abstract}
The purpose of this study is to determine the effect of high temperatures on rigid PVC tubes used in industrial areas that the release of very hot fluids is prevalent. Three different aging protocols $\left(\mathrm{T}=80{ }^{\circ} \mathrm{C}, \mathrm{T}=100{ }^{\circ} \mathrm{C}\right.$, and $\left.\mathrm{T}=120{ }^{\circ} \mathrm{C}\right)$ were performed for 90 days at temperatures near and above the glass transition temperature.

It appeared that these temperatures increased the structural changes and modified the chemical structure of rigid PVC tube. Indeed, the infrared analysis revealed the formation of a significant amount of oxidation products (conjugated and isolated ketones, esters) during aging due to the oxidation and chain scission reactions. The propagation of polyene sequences was more critical in the $120^{\circ} \mathrm{C}$ aging protocol than other protocols. These sequences almost certainly played a role in forming new chemical bonds via the bimolecular interaction of in-chain radicals, which resulted in crosslinking. On the other hand, the crosslinking and chain scission reactions are alternatively more important for the sample aged at $100{ }^{\circ} \mathrm{C}$. During the first and last 30 days of aging, the conjugated double bonds increased indicating that crosslinking reactions occurred. While the oxidation products developed till 60 days of aging, showing that the chain scissions are more important during this final period. At $80{ }^{\circ} \mathrm{C}$, the chain scission reactions are more effective in the first 30 days of aging while the crosslinking reactions became more important just after 30 days. Moreover, the stabilization mechanism provided by the stabilizing system is also affected by the aging temperature.
\end{abstract}

Keywords: rigid PVC tube, thermal aging, glass transition, infrared analysis.

\section{INTRODUCTION}

Nowadays, PVC pipe is one of the most popular thermoplastic used in the world, which has received a great attention for research in the field of modification, development and degradation. The thermal instability of $\mathrm{PVC}$ resulting from the presence of oxygen groups in macromolecular chains has also been notified in the past decades. In all cases, the first step in degradation process of PVC is caused by the zip elimination of $\mathrm{HCl}$ from the primary chain, as well as by the inevitable formation of conjugated polyene sequences into the polymer chains occurring either during processing or use $[1,2]$. (S.R. Leijenaa et al 1985) suggested that the crosslinking mechanism of the PVC molecules at processing temperatures is due by Diels-Alder additions of polyenes formed. However, the experimental evidence for participation of polyenes in crosslinking is still limited [3].
In addition, the peroxides formed by polyenes reaction of with oxygen are followed by the formation of new functional carbonyl groups which lower the thermal stability of the material $[1,4]$.

PVC tubes are used for water transportation in several fields (industrial, agricultural, etc.....) and are subjected to a variety of environmental factors; one of the most important among them is very probably high service temperature.

In our previous studies we performed different aging protocols on pristine PVC, dry-blend and rigid (u-PVC) tube at different temperatures. For the protocols realized on (u-PVC) at temperatures below glass transition $(\mathrm{Tg})$ (Hadj amar et al 2021), it has been showed that the aging temperature increased the rate of oxidation reaction and affected adversely the microstructure of (u-PVC) because of chain scission and crosslinking reactions. 
The present study aims to reveal the effect of high temperatures $\left(\mathrm{T}=80{ }^{\circ} \mathrm{C}, \mathrm{T}=100{ }^{\circ} \mathrm{C}\right.$, and $\left.\mathrm{T}=120^{\circ} \mathrm{C}\right)$ on the structural changes caused by oxidation, crosslinking and chain scission reactions despite the use of a stabilization system, that we tried to reveal by using FTIR-ATR spectroscopy and mathematical curve-fitting analysis.

\section{EXPERIMENTAL}

\subsection{Materiel}

The material used for the present investigation is rigid (u-PVC) tube manufactured by PLASTUB-society (Ghardaïa, Algeria) according to the ISO: EN-1452-2 standard, with outside diameter $=63 \mathrm{~mm}$, thickness $=3$ $\mathrm{mm} \pm 0.3$ and nominal pressure $=10$ bars $[5,6]$.

The dry-blend mixture of the processed tube consisted of $86 \%$ PVC powder; $2 \%$ stabilizer systems (tribasic lead); $5 \%$ Calcium carbonate filler and 7\% Carbon black $[5,6]$.

\subsection{Aging protocols}

Several samples of (u-PVC) were picked-up from the original rigid PVC tube by using a mill cutter and exposed to three thermal aging protocols were performed on the samples at respectively $80^{\circ} \mathrm{C}, 100{ }^{\circ} \mathrm{C}$ and $120^{\circ} \mathrm{C}$ in thermo-regulated ovens open to the atmosphere, the samples are taken every 30 days during 90 days.

\subsection{Infrared analysis (FTIR)}

A "spectrum Two" FTIR spectrometer maintained by Perkin Elmer (USA), equipped with the UATR-Two was applied to perform the infrared analysis on the aged samples of (u-PVC) gathered from the three aging protocols. The FTIR-ATR analysis was carried out on the sample surface put in contact with a diamond crystal. The infrared spectra were collected in the transmission mode over the wavenumber range [4000-400 $\left.\mathrm{cm}^{-1}\right]$, optical resolution $=4 \mathrm{~cm}^{-1}$ and scan repetitions $=32$. The optical density (OD) was determined from the following equation Eq. (1) [5-7].

$\mathrm{OD}=\ln \left(\frac{\mathrm{I}_{0}}{\mathrm{I}}\right)$

Where $\mathrm{I}_{0}$ is the reference infrared intensity corresponding to the baseline of the spectrum at the peak wavenumber and $\mathrm{I}$ is the minimum intensity at the base of the peak [57].

\subsubsection{Mathematical curve-fitting}

Mathematical curve-fitting was performed using the second derivative method in the Origin.Pro software package (version 9.0) to characterize the different species constituting the complexes absorption bands which appeared in the FTIR spectrum.
The fit quality is controlled using the determination coefficient, with, with $\mathrm{R}^{2}>0.998$ for the absorption band of each sample. The residual sum of the squares was determined to be Chi-square $<10^{-5}[5,6,8]$.

\section{RESULTS AND DISCUSSION}

\subsection{Tube color change}

In practice, discoloration is normally the first and the most visible effect of aging. Test pieces were taken from the same (u-PVC) tube, and were aged according to the different aging protocols previously described. In Figure 1 are reported the photos showing the progressive discoloration of the test pieces aged at respectively (80 ${ }^{\circ} \mathrm{C}, 100{ }^{\circ} \mathrm{C}$ and $120{ }^{\circ} \mathrm{C}$ ) for different aging stages. It appears that the samples color changed gradually from gray to purple-gray, to become brown even black in the last aging stages. It has been shown that the formation of long polyenic sequences ( $>5$ units) absorbs light in the visible range. The longer the polyenic sequences the darker the color. The polyene sequences are the results of a zip dehydrochlorination process along the molecular chain. This effect becomes more intense when the aging temperature becomes close or just above the glass transition temperature ( $\mathrm{Tg})$ [9-11].

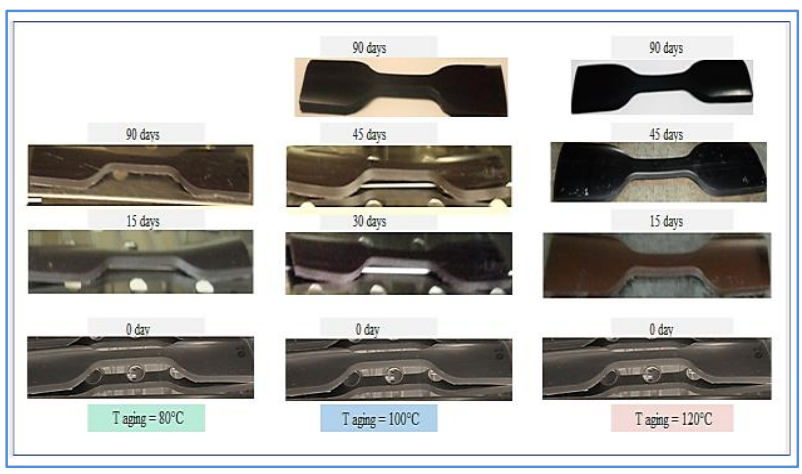

Figure 1: Coloration changes of (u-PVC) test pieces aged at $\left(80,100\right.$ and $\left.120{ }^{\circ} \mathrm{C}\right)$ versus aging time [12].

\subsection{Changes in molecular structure}

Transportation of very hot liquids in industry zones can be the occurrence of structural damages caused to PVC tubes. Exposure of (u-PVC) to three different aging temperatures to simulate the industrial working condition of tubes has shown a change of IR spectrum in the wavenumber range $\left[1500-1800 \mathrm{~cm}^{-1}\right]$. Therefore the aim of the infrared spectroscopy analysis was to show how aging of rigid PVC occurs and it is affected when exposed to increasing temperatures via different aging protocols. Because the aging process is mainly governed by polyenes formation, oxidation, chain scission and crosslinking....etc. Moreover, the stabilization system and the fillers added to the PVC recipe of the dry blend have non negligible effects. Indeed, the appearance of many shoulders in wavenumbers range $\left[1500-1800 \mathrm{~cm}^{-1}\right]$ 
of the IR spectrum indicates the formation of different groups of carbonyl, carboxylates and polyenes. To reveal the sub-peaks hidden in the different absorption band of the above described interval, deconvolution by curve fitting brings an original approach to the IR identification of the chemical species developing or disappearing.

Therefore, we tried firstly to identify the sub-peaks existing in the interval [1500-1800 $\left.\mathrm{cm}^{-1}\right]$ specific to the unaged rigid PVC got just after processing (Figure 2).

In Figure 2, it can be distinguished three large absorption bands which correspond to:

(a) The carboxylates region [1500-1600 $\left.\mathrm{cm}^{-1}\right]$ : Two peaks appearing at 1540 and $1576 \mathrm{~cm}^{-1}$, the first corresponds to the stretching vibration of carboxylate $\left(\mathrm{COO}^{-}\right)$groups belonging to the lead stearate $\left(\mathrm{PbSt}_{2}\right)$, while the second corresponds to the stretching vibration of carboxylate $\left(\mathrm{COO}^{-}\right)$groups belonging to calcium stearate $\left(\mathrm{CaSt}_{2}\right)$. Both products are components of the stabilizer system [5, 6, 13-16].

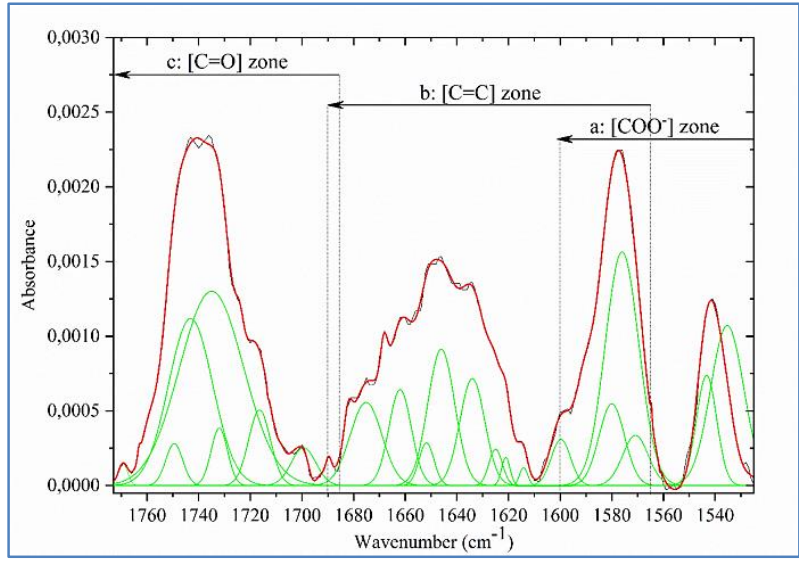

Figure 2: IR spectra curve-fitting of unaged (u-PVC)

(b) The unsaturation region [1565-1690 $\left.\mathrm{cm}^{-1}\right]$ : two types of bands appeared at $\left(1580,1599,1639,1675 \mathrm{~cm}^{-}\right.$ $\left.{ }^{1}\right)$ and at $\left(1646,1651,1662 \mathrm{~cm}^{-1}\right)$, the first is attributed to the stretching vibration of conjugated double bonds and the second correspond to the stretching vibration of isolated double bonds respectively [17-19]. According to several authors, the formation of conjugated polyenes occurs via the zip elimination of $\mathrm{HCl}$ from the PVC chain (Figure 3) [1].

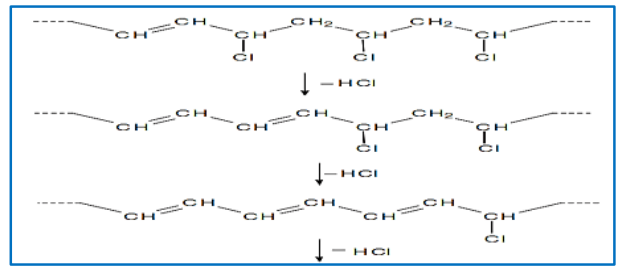

Figure 3: Zip-elimination of HCl [19].

(c) The carbonyl region [1685-1774 $\left.\mathrm{cm}^{-1}\right]$ : Several peaks appear at 1699, 1716, 1730, 1735 and $1742 \mathrm{~cm}^{-1}$. They represent the carbonyl $(\mathrm{C}=\mathrm{O})$ stretching vibration of conjugated ketone, isolated ketone, ester and carboxylic acid [6, 17, 20-22].

The conjugated $\left(1606,1699 \mathrm{~cm}^{-1}\right)$ and isolated ketones $\left(1725 \mathrm{~cm}^{-1}\right)$ are formed successively by the scission of the hydroperoxides. These latter were observed as the primary oxidation products obtained by radical oxidation reactions (by surrounding oxygen) of the polyene sequences and occurring during processing of the tubes. The ketones are also the precursor of ester groups (1735, $1742 \mathrm{~cm}^{-1}$ ) by their reaction with a macro-alkoxy or peroxy radicals (Figure 4) [17, 21, 23, 24].

The esters and the carboxylic acids $\left(1716 \mathrm{~cm}^{-1}\right)$ can also be produced via the stabilization reactions of the stabilizer system which replaces labile chlorines and scavenge $\mathrm{HCl}$ molecules, consequently to the combined effect of the shearing forces of the extrusion-screw and the heat delivered by the heaters of the barrel [5].

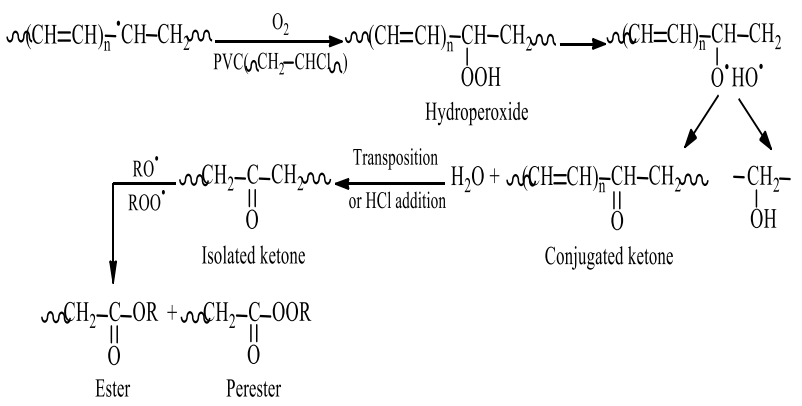

Figure 4: Oxidation reactions of the polyene sequences

\subsubsection{Evolution of the polyene sequences and carbonyl groups}

In Figure 5 the IR spectra are reported with curve fitting in the range $\left[1500-1800 \mathrm{~cm}^{-1}\right]$ for (u-PVC) samples exposed to $80{ }^{\circ} \mathrm{C}$, with four aging stages $(0,30$, 60 and 90 days). It was observed that the integrated area of sub-peaks corresponding to the carboxylate groups $\left(1540 \mathrm{~cm}^{-1}, 1576 \mathrm{~cm}^{-1}\right)$ decreased with aging time, indicating that the stabilizer is consumed by providing its stabilization action to the molecular PVC structure. The change of the double bonds envelope and its sub-peaks area at $(1580,1599,1639,1646,1651,1662$ and 1675 $\mathrm{cm}^{-1}$ ) is almost irregular, because of the changing rate of dehydrochlorination, $\mathrm{HCl}$-scavenging and oxidation process with aging time. The (graph A30 ) shows that the double bonds peak-area decreased during the first 30 days of aging, coinciding with the increase of each of conjugated ketones $\left(1606 \mathrm{~cm}^{-1}\right)$, isolated ketones $(1725$ $\left.\mathrm{cm}^{-1}\right)$ and esters $\left(1742 \mathrm{~cm}^{-1}\right)$. This allows understanding that the polyenes are oxidized (see Figure 4). After 30 days of aging, the double bonds peak-area increased till the end of aging (graphs A60 and A90), while the ketone groups decreased, indicating that the oxidation reactions were less effective after the 30 first days. 


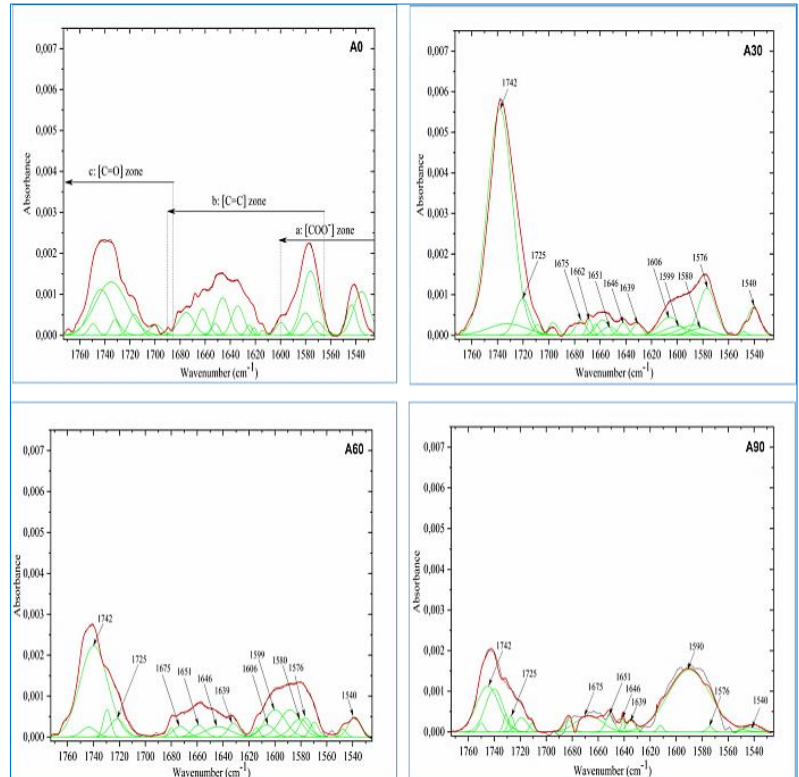

Figure 5: Infrared spectra curve-fitting of (u-PVC) exposed to $80{ }^{\circ} \mathrm{C}$ with $(0,30,60$ and 90 days) aging times.

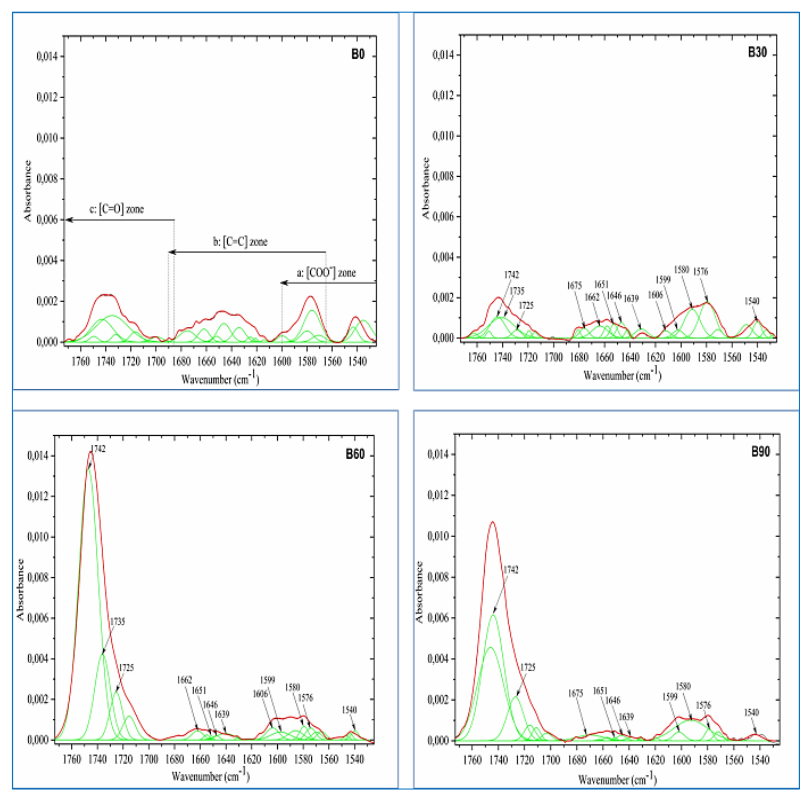

Figure 6: Infrared spectra curve-fitting of (u-PVC) exposed to $100{ }^{\circ} \mathrm{C}$ with $(0,30,60$ and 90 days) aging times.

In Figure 6 the IR spectra are reported with curve fitting in the range [1500-1800 $\left.\mathrm{cm}^{-1}\right]$ for (u-PVC) samples exposed to $100{ }^{\circ} \mathrm{C}$, with four aging stages $(0,30$, 60 and 90 days). The vibrations of the double bonds having characteristic sub-peaks at $(1580,1599,1639$, 1646, 1651, 1662 and $1675 \mathrm{~cm}^{-1}$ ) saw their integrated area changing irregularly. While those of at 1580 and $1599 \mathrm{~cm}^{-1}$ corresponding to the vibrations of the conjugated double bonds increased during the first 30 days (B30 graph). During the same period, the vibration of the isolated double bonds $\left(1646 \mathrm{~cm}^{-1}\right)$ decreased noticeably. The conjugated and isolated ketones (1606 $\mathrm{cm}^{-1}, 1725 \mathrm{~cm}^{-1}$ ) grown during the first 60 days to a higher value compared to the samples exposed to $80{ }^{\circ} \mathrm{C}$, despite the isolated ketones knew a much higher increase. The esters $\left(1735,1742 \mathrm{~cm}^{-1}\right)$ increased dramatically during the first 60 days to a significant value, this evolution has shown that the oxidation reaction is very important in this protocol. At 90 days, the sub-peaks area of the conjugated ketones and esters decreased indicating the consummation of the oxidation products.

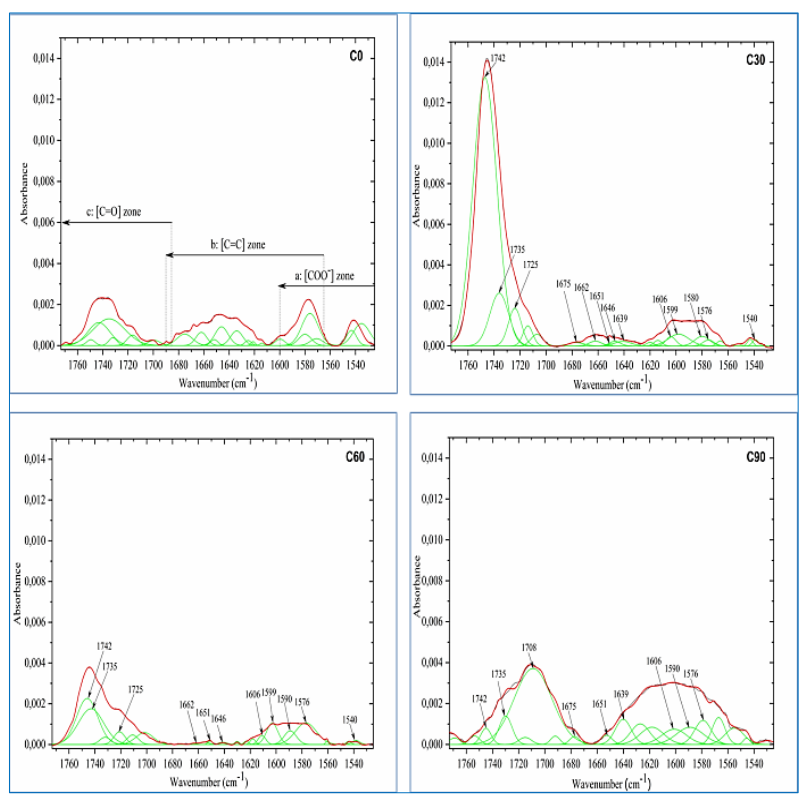

Figure 7: Infrared spectra curve-fitting of (u-PVC) exposed to $120{ }^{\circ} \mathrm{C}$ with $(0,30,60$ and 90 days) aging times.

Figure 7 shows the infrared spectra curve fitting of (uPVC) samples exposed to $120^{\circ} \mathrm{C}$, for different aging times. Comparatively to the previous protocols the two sub-peaks corresponding to the carboxylates vibration in the stabilizer system $\left(1540 \mathrm{~cm}^{-1}, 1576 \mathrm{~cm}^{-1}\right)$ instead of a continuous decrease varied irregularly. The first one characteristic to lead stearate decreases more rapidly comparatively to the other protocols. Indeed, the amount of lead stearate consumed during the first 30 days is equivalent to that consumed in 90 days in the protocol carried out at $80{ }^{\circ} \mathrm{C}$. However, the second peak characteristic to calcium stearate decreased during the first 30 days. Just after, it increased surprisingly until 60 days. Beyond this limit of time, it decreased again until the end of the aging protocol. The increase of the calcium stearate in the middle of the aging protocol suggests that the carboxylate of the fatty acid either of the stabilizer system or provided by the scavenging reactions with the calcium carbonate filler leading thus to the formation of calcium stearate (Hadj amar et al 2019, paragraph 3.3, Eq.12) [5, 6]. The isolated double bonds $\left(1646,1662 \mathrm{~cm}^{-}\right.$ $\left.{ }^{1}\right)$ decreased throughout the aging protocol. While, the integrated area of the conjugated double bonds vibration $\left(1580,1599 \mathrm{~cm}^{-1}\right)$ increased. The conjugated ketones $\left(1606,1699 \mathrm{~cm}^{-1}\right)$ also increased during the first 60 days, 
while the isolated ketones $\left(1725 \mathrm{~cm}^{-1}\right)$ increased only during the first 30 days because just after they were transformed into ester groups $\left(1735,1742 \mathrm{~cm}^{-1}\right)$. The graph C90 shows a broad peak at $1708 \mathrm{~cm}^{-1}$, with a relatively large area, it very probably corresponds to the carbonyl vibration of dimeric acid carboxylic formed via $\mathrm{HCl}$-scavenging or by the degradation of ester groups (Hadj amar et al 2019, paragraph 3.2, Eq.6, Eq.8 and Eq.10) [5, 6].

\section{CONCLUSION}

This study deals with the effect of thermal aging on the molecular structure of (u-PVC) tube exposed to high temperatures $\left(80{ }^{\circ} \mathrm{C}, 100{ }^{\circ} \mathrm{C}\right.$ and $\left.120^{\circ} \mathrm{C}\right)$ situated above the glass transition. Thermal aging at different aging protocols carried out on rigid (u-PVC) shown noticeable microstructural changes.

The sample changes undergone at the aging protocol of $120{ }^{\circ} \mathrm{C}$ were the most deleterious. Whereas the infrared analysis has shown the formation of significant amount of oxidation products (esters, conjugated and isolated ketones) developing during oxidation and chain scissions reactions. The propagation of the polyene sequences was also accelerated during aging, that participate very probably to the formation of new chemical bonds by bimolecular interaction of in-chain radicals leading to crosslinking.

For the sample aged at $100{ }^{\circ} \mathrm{C}$, the two processes of chain scissions and crosslinking are alternatively more important; the FTIR-ATR spectra showed that the conjugated double bonds increased during the first 30 days, while the oxidation products (conjugated and isolated ketones, esters) developed till 60 days of aging, showing that chain scissions are more important during this period. After 60 days, conjugated double bonds slightly increased, indicating that crosslinking reactions occurred during the first and the last 30 days of aging.

At aging temperature around $80{ }^{\circ} \mathrm{C}$, chain scission reactions are more effective during the first 30 days of aging while crosslinking reactions became more important just after 30 days.

It can be concluded that aging, for a relatively long period of time and at elevated temperature (i.e. at $\mathrm{T}>\mathrm{Tg}$ ), has considerable adverse effects on the molecular structure of rigid PVC. It leads essentially to different processes such as dehydrochlorination, polyene propagation, crosslinking, oxidations and chain scission reactions. All those processes may occur simultaneously but with different rates according to the aging temperature. Moreover, the stabilization mechanism provided by the stabilization system is also affected by the aging temperature, adding as such to the difficulty of understanding on one hand the aging mechanism of PVC and on the other hand how the stabilization mechanism occurs.
In fact, it can be recommended to perform the aging protocols on tubes soaked in water at different temperatures with regular sampling in order to reveal the nature of the migrating additives towards water by hydrolysis.

\section{REFERENCES}

[1] J. Liu, Y. Lv , Z. Luo , H. Wang , Wei Z, Molecular chain model construction, thermo-stability, and thermo-oxidative degradation mechanism of poly(vinyl chloride), The Royal Society of Chemistry RSC Advence, 2016, (6):31898-31905. DOI: https://doi.org/10.1 039/c6ra02354a

[2] S.R. Leoenaar, C.J.M. Heuvel, W.G.B. Huysmans, Polyene formation and crosslinking during the thermal degradation of poly(viny1 chloride), Makromol Chem, 1985, (186):1549-1553.

[3] B.B. Troitskii, L.S. Troitskaya, V.N. Myakov, A.F. lepaev. Mechanism of the thermal degradation of Poly(vinyl chloride), J Polym Sci, 1973; (42): 13471361.

[4] G. Szarka, B. Iván, Degradative transformation of poly(vinyl chloride) under mild oxidative conditions, American Chemical Society, 2009; pp. 219-226, Chapter 19.

[5] Z. Hadj amar, S.F. Chabira, M. Sebaa, A. Benchatti, Structural changes undergone during thermal aging and/or processing of unstabilized, dry-blend and rigid PVC investigated by FTIR-ATR and curve fitting, Annales de Chimie: Science des Materiaux, $2019 \quad$; 43(1):59-68. DOI: https://doi.org/10.18280/acsm.430109

[6] Z. Hadj amar, SF. Chabira, M. Sebaa, Thermal aging effects on the microstructure of rigid PVC tubes used for water transportation in sub-saharan region. Materials Today: Proceedings, https://doi.org/10.1016/j.matpr.2021.09.025.

[7] S.F. Chabira, M. Sebaa, C. G'sell, Oxidation and crosslinking processes during thermal aging of lowdensity polyethylene films, J Appl Polym Sci, 2011;124:5200-5208. DOI: https://doi.org/10.1002/app.34080

[8] W.Yagoubi, A. Abdelhafidi, M. Sebaa, S.F. Chabira, Identification of carbonyl species of weathered LDPE films by curve fitting and derivative analysis of IR spectra, Polym Test J , 2015; 44:37-48. DOI: https://doi.org/10.1016/j.polymertesting.2015.03.0 08

[9] J.L. Gardette, J. Lemaire, Acquis récents dans l'étude $\mathrm{du}$ photovieillissement du PVC. Caoutchoucs et plastiques, 1987; 672:133. 
[10] D. Braun, Internal stabilization of poly (vinyl chloride), Stabilization of polymers and stabilizer processes, Washington: American Chemistry Society; 1968.

[11] C. Decker, Photodegradation of PVC. In: Owen ED, editors. Degradation and stabilisation of PVC. London and New York: Elsevier Applied Science Publishing Co; 1984. Chapter 3.

[12] Z. Hadj amar, S.F Chabira, M. Sebaa, Vieillissement Thermique de Tubes en PVC Rigide pour le Transport de l'Eau. Revue des Sciences et Sciences de l'Ingénieur, 2015; 5(1):19-23.

[13] M.J. Plater, B.D. Silva, T. Gelbrich, M.B. Hursthouse, C.L. Higgitt, D.R. Saunders, The characterisation of lead fatty acid soaps in protrusions in aged traditional oil paint, Polyhedron, $2003 ; 22: 3171-3179$.

[14] R. Benavides, M. Edge, N.S. Allen, The mode of action of metal stearate stabilisers in poly (vinyl chloride). I. Influence of pre-heating on melt complexation, Polym Degrad Stab, 1994; 44:375378. DOI: https://doi.org/10.1016/01413910(94)90096-5

[15] R. Kalouskova, M. Novotna, Z. Vymazal, Investigation of thermal stabilization of poly(vinyl chloride) by lead stearate and its combination with synthetic hydrotalcite, Polym Degrad Stab, 2004; 85: 903-909. DOI: https://doi.org/10.1016/j.polymdegradstab.2004.04. 008

[16] M. Gönen, S. Öztürk, D. Balköse, S. Okur, S. Ülku, Preparation and characterization of calcium stearate powders and films prepared by precipitation and Langmuir- Blodgett techniques, Ind Eng Chem Res. 2010;49: 1732-1736. DOI: https://doi.org/10.1021/ie901437d

[17] J.L. Gardette, J. Lemaire, Photothermal and thermal oxidations of rigid, plasticized and pigmented poly (vinyl chloride), Polym Degrad Stab, 1991; 34:135167. DOI: https://doi.org/10.1016/10.1016/01413910(91)90117-A

[18] A.A. Balakit, A. Ahmed, G.A. El-Hiti, K. Smith, E. Yousif, Synthesis of new thiophene derivatives and their use as photostabilizers for rigid poly(vinylchloride), Int J Polym Sci, 2015: 1-10. DOI: http://dx.doi.org/10.1155/2015/510390

[19] T. Szakacs, B. Ivan, Epoxidation of thermally degraded poly(vinyl chloride), Polym Degrad Stab, 2004; 85:1035-1039. DOI: 10.1016/j.polymdegradstab.2003.04.003
[20] W.F. Maddams, Spectroscopic and chemical investigations of PVC structure. In: Owen ED, editors, Degradation and stabilisation of PVC. London and New York: Elsevier Applied Science Publishing Co; 1984. Chapter 4.

[21] C. Decker, Photodegradation of PVC. In: Owen ED, editors. Degradation and stabilisation of PVC. London and New York: Elsevier Applied Science Publishing Co; 1984. Chapter 3.

[22] M. Gilbert, J.C. Vyvoda, Thermal analysis technique for investigating gelation of rigid PVC compounds, Polymer, 1981; 22:1134-1136.

[23] T. Hjertberg, E.M. Sorvik, Thermal degradation of PVC, In: Owen ED, editors. Degradation and stabilisation of PVC. London and New York: Elsevier Applied Science Publishing Co; 1984. Chapter 2.

[24] W.C. Geddes, Mechanism of PVC degradation, Rubber Chem Technol. 1967:178-213. 